\title{
Avaliação de diferentes meios de cultura na esporulação de Scytalidium lignicola
}

\author{
Juliana Paiva Carnaúba ${ }^{1}$, Márcio Félix Sobral ${ }^{2}$, Edna Peixoto da Rocha Amorim³ ${ }^{3}$ Julio Cesar da Silva ${ }^{4}$, Vanderley \\ Borges dos Santos ${ }^{5}$, Kátia Cilene da Silva Félix ${ }^{6}$
}

${ }^{1}$ Estudante de Doutorado em Fitopatologia, UFRPE/ Bolsista CAPES. ${ }^{2}$ Estudante de Mestrado em Fitopatologia, UFRPE/ Bolsista CAPES. ${ }^{3}$ Universidade Federal de Alagoas, Centro de Ciências Agrárias, Departamento de Fitotecnia e Fitossanidade, CEP 57100-000, Rio Largo, AL. ${ }^{4}$ Estudante de Mestrado em Agronomia, CECA-UFAL/ Bolsista Fapeal. ${ }^{5}$ Estudante de Mestrado em Agronomia, CECA-UFAL/ Bolsista CAPES. ${ }^{6}$ Estudante de Mestrado em Fitopatologia, UFRPE. E-mail: jcarnauba@hotmail.com

Autor para correspondência: Juliana Paiva Carnaúba

Data de chegada: 19/09/2005. Aceito para publicação em: 24/10/2006.

\section{RESUMO}

Carnaúba, J.P.; Sobral, M.F.; Amorim, E.P. da R.; Silva, J.C.; Santos, V.B.; Félix, K.C. da S.; Avaliação de diferentes meios de cultura na esporulação de Scytalidium lignicola. Summa Phytopathologica, v.33, n.2, p.199-200, 2007.

Scytalidium lignicola é um fungo que causa podridão negra em raízes e caules de mandioca. A esporulação de $S$. lignicola foi avaliada em 8 meios de cultura - BDA, SA, AvA, BSA, LCA, suco V-8, Mandioca-agar (MAND-A) e MA - sob regime de alternância de luz (12h claro/12h escuro) e 3 temperaturas $\left(2528\right.$ e $\left.30^{\circ} \mathrm{C}\right)$. Discos de $5 \mathrm{~mm}$ de diâmetro retirados da borda da colônia cultivada em meio BDA, após 5 dias de incubação a $28^{\circ} \mathrm{C}$, foram transferidos para o centro de placas de Petri contendo $15 \mathrm{~mL}$ de cada meio com inibidores seletivos. Após 5 dias de incubação, os esporos foram quantificados em contagens realizadas em câmara de Neubauer. O experimento seguiu delineamento inteiramente casualizado em esquema fatorial $8 \times 3$ (Meios $\times$ Temperaturas). Observou-se que houve diferença significativa apenas para os meios de cultura, não havendo diferença entre as temperaturas testadas. A esporulação de S. lignicola foi superior nos meios suco V-8, BDA, MAND-A, AvA, BSA e SA, não diferindo entre si estatisticamente. Enquanto nos meios MA e LCA ocorreram as menores esporulações, também não havendo diferença entre si.

Palavras-chave adicionais: Podridão-negra, mandioca, fungo.

\begin{abstract}
Carnaúba, J.P.; Sobral, M.F.; Amorim, E.P. da R.; Silva, J.C.; Santos, V.B.; Félix, K.C. da S. Evaluation of different culture media on the sporulation of Scytalidium lignicola. Summa Phytopathologica, v.33, n.2, p.199-200, 2007.
\end{abstract}

Scytalidium lignicola causes black root rot and stem rot on cassava plants. The sporulation of $S$. lignicola was evaluated in 8 different culture media as following: potato-dextrose-agar (PDA), soybeanagar, oat-extract-agar, potato-sucrose-agar (PSA), coconutextract-agar, $\mathrm{V}-8$ juice-agar, cassava-agar and corn meal-agar, under light alternation (12h light $/ 12 \mathrm{~h}$ dark) at three different temperatures 25,28 and $30^{\circ} \mathrm{C}$. Discs measuring $5 \mathrm{~mm}$ were removed from the border of a 5-days old fungus culture in PDA. These discs were transferred to the center of Petri dishes containing $15 \mathrm{~mL}$ of each media with selective inhibitors.
After 5 days of incubation, the spores were counted in a Neubauer chamber. The experiment was installed using a randomized block design in a factorial 8 media $\times 3$ temperatures scheme. It was observed that the only significant factor was the media culture, V-8 juice-agar, PDA, cassava-agar, oat-extract-agar, PSA, and soybean-agar media gave the best fungus sporulation without significant difference among them. There was no significant difference between the corn meal-agar and coconutextract-agar media for fungus sporulation. On these media, fungus sporulation was the lowest compared to the other media.

Additional keywords: black roor rot, stem rot cassava, fungus.

O fungo Scytalidium lignicola Pesante causa podridão negra em raízes e caules de mandioca. A presença deste patógeno foi verificada pela primeira vez no estado de Pernambuco (4), seguido do estado do Pará (9) e no estado de Alagoas (7)

A composição do meio de cultura determina a quantidade e qualidade do crescimento micelial e esporulação dos fitopatógenos. Além dos meios de cultura, a temperatura e luminosidade são fatores essenciais para estimular a esporulação dos patógenos (2). Quando um fungo cresce bem em um substrato e não em outro, acredita-se que metabólitos específicos estejam envolvidos (6).

A esporulação é um processo de diferenciação mais específico, no qual, estão envolvidas as células reprodutivas afetadas por modificações morfológicas, fisiológicas e bioquímicas (3).
Neste trabalho, foi avaliada a esporulação de S. lignicola em diferentes meios de cultura utilizando 3 temperaturas, sob regime de alternância luminosa.

O trabalho foi realizado no Laboratório de Fitopatologia do Centro de Ciências Agrárias, da Universidade Federal de Alagoas, no ano de 2005. O isolado de $S$. lignicola foi obtido de raízes de mandioca com sintomas característicos de podridão negra, provenientes do município de Boca da Mata - AL.

Foram utilizados 8 meios de cultura conforme apresentado na Tabela 1, preparados de acordo com sua descrição na literatura. Todos os meios foram autoclavados a $120^{\circ} \mathrm{C}$ por 20 minutos. Cada placa de Petri recebeu $15 \mathrm{~mL}$ de meio contendo inibidor seletivo.

O meio mandioca-ágar foi preparado, utilizando $200 \mathrm{~g}$ de mandioca, 
Tabela 1. Meios de cultura utilizados na esporulação de Scytalidium lignicola e preparados conforme descrição na literatura.

\begin{tabular}{ll}
\hline Meio de Cultura & Referência \\
\hline Batata-dextrose-agar (BDA) & Riker \& Riker, 1936 (14) In: Menezes \& Silva-Hanlin, 1997. \\
Soja-agar (SA) & Smoot et al., 1958 (16) In: Menezes \& Silva-Hanlin, 1997 \\
Aveia-agar (AvA) & Gooding \& Lucas, 1959 (5) In: Menezes \& Silva-Hanlin, 1997 \\
Batata-sacarose-agar (BSA) & Booth, 1977 In: Menezes \& Silva-Hanlin, 1997 \\
Leite de coco-agar (LCA) & Menezes \& Silva-Hanlin, 1997 (10) \\
Suco V-8 agar (V-8) & Romero \& Gallegly, 1963 (15) In: Menezes \& Silva-Hanlin, 1997 \\
Mandioca-agar (MAND-A) & Carnaúba, 2005 \\
Milho-agar (MA) & Plaats-Niterink, 1981 (13) In: Menezes \& Silva-Hanlin, 1997 \\
\hline
\end{tabular}

Tabela 2 - Médias de esporulação de Scytalidium lignicola em diferentes meios de cultura, em condições de alternância luminosa e temperatura de $28^{\circ}$ C.

Meio de Cultura

Esporulação (Conídios /mL )

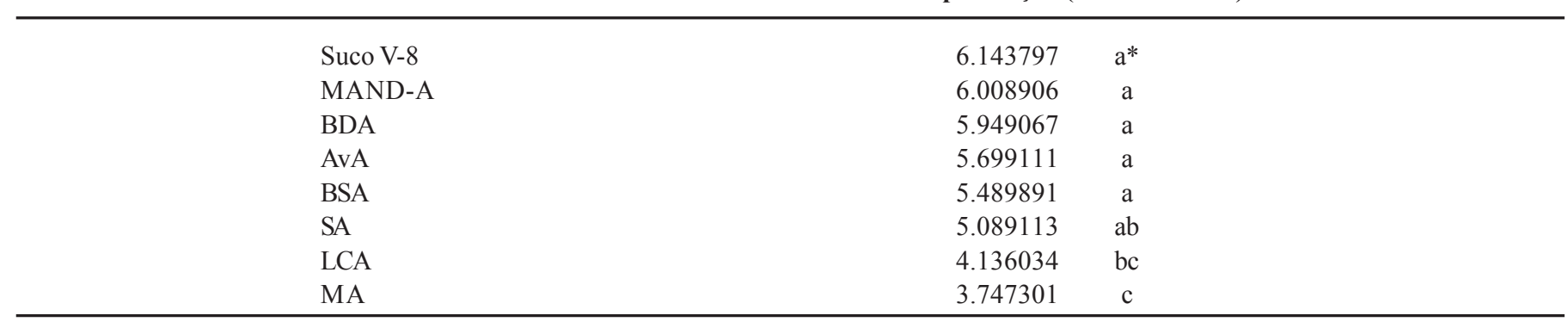

** Médias seguidas pela mesma letra, não diferem entre si, pelo teste de Tukey a $5 \%$ de probabilidade.

$20 \mathrm{~g}$ de dextrose, $17 \mathrm{~g}$ de agar e $1000 \mathrm{~mL}$ de água destilada.

Da cultura pura do isolado, cultivada em meio batata-dextroseagar (BDA) por 5 dias a $28^{\circ} \mathrm{C}$, foram retirados discos de $5 \mathrm{~mm}$ de diâmetro e depositados no centro de cada placa de Petri. As placas foram incubadas em estufa B.O.D. sob 3 temperaturas $\left(25^{\circ}, 28^{\circ}\right.$ e $\left.30^{\circ} \mathrm{C}\right)$ e alternância luminosa $(12 \mathrm{~h})$.

Para a quantificação dos esporos, foram adicionados $10 \mathrm{~mL}$ de água destilada autoclavada, contendo Tween 80 a $0,05 \%$, por placa de Petri, utilizando-se escova de dente para facilitar a liberação dos conídios. A suspensão obtida foi filtrada em dupla camada de gaze e a concentração dos esporos determinada através da contagem em microscópico ótico utilizando câmara de Neubauer, estabelecendo-se uma média de 4 leituras.

O experimento seguiu delineamento inteiramente casualizado em esquema fatorial $8 \times 3$ com 4 repetições, onde cada repetição foi representada por uma placa de Petri. Foi utilizado o teste de Tukey com transformação de logaritmo base 10 de Y - $\log 10$ (Y).

Segundo resultados da análise de variância, houve diferença significativa, de acordo com o teste $\mathrm{F}$ a $1 \%$, apenas para o meio de cultura, não havendo diferença entre as 3 temperaturas testadas.

Conforme a Tabela 2, através do teste de Tukey a 5\%, conclui-se que a esporulação de $S$. lignicola foi significativamente superior nos meios: suco V-8, MAND-A, BDA, AvA, BSA e SA, entretanto, não diferiram entre si estatisticamente. Já nos meios MA e LCA ocorreram as menores esporulações, também não havendo diferenças estatísticas entre si.

Segundo Nozaki et al. (8), nem sempre as condições que favorecem o crescimento do fungo são as mesmas para esporulação. Sabe-se ainda que, alguns meios de cultura são mais favoráveis para a esporulação de fungos que outros. A necessidade de luz para o crescimento e esporulação de fungos é muito variável, até mesmo entre isolados da mesma espécie (5). Alguns esporulam melhor na presença de luz contínua ou em escuro contínuo (1).

\section{REFERÊNCIAS BIBLIOGRÁFICAS}

1. Cooperman, C. J.; Jenkins, S. F. Conditions influencing growth sporulation of Cercospora asparagi blight development in Asparagus. Phytopathology, St. Paul, v. 76, n. 6, p. 617-622, 1986.

2. Dhingra, O.D.; Sinclair, J.B. Basic plant pathology methods. Lewis: Publishers Boca Raton, Flórida, 1995.

3. Griffin, D.H. Fungal Physiology, New York: Jonh Wiley, 1993, v.2. 458p. In: Castro, N.R. \& Coelho, R.S.B. Caracterização fisiológica de isolados de Cercospora cruenta em diferentes meios de cultura. Summa Phytopathologica, v.26, p. 466-471, 2000.

4. Laranjeira, D.; Santos, E.O. dos; Mariano, R. de L.R.; Barros, S.T. Ocorrência da podridão negra da maniva e raiz da mandioca (Manihot esculenta) causada por Scytalidium lignicola no estado de Pernambuco, Brasil. Fitopatologia Brasileira, Brasília, v. 19, n.3, p. 466-469, 1994.

5. Masangkay, R. F.; Paulitz, T. C.; Hallet, S. G.; Watson, A. K. Characterization of sporulation of Alternaria alternata f. sp. sphenocleae. Biocontrol Science and Technology, Oxford, v. 10, n. 4 , p. $385-397,2000$.

6. Menezes, M.; Silva-Hanlin, D.M.W. Guia prático para fungos fitopatogênicos. Recife: UFRPE, 1997. 106p.

7. Muniz, M. de F.S.; Santiago, A.D.; Fukuda, C.; Menezes, M. Scytalidium lignicola: patógeno da mandioca no estado de Alagoas. Summa Phytopathologica, Jaboticabal, v. 25, p. 156-158, 1999.

8. Nozaki, M. de H.; Camargo, M. e Barreto, M. Caracterização de Diaporthe citri em diferentes meios de cultura, condições de temperatura e luminosidade. Fitopatologia Brasileira, Brasília, v. 29 n.4, p. 429-432, 2004.

9. Trindade, D.R.; Poltronieri, L.S.; Albuquerque, F.C.; Poltronieri, M.C. Ocorrência do fungo Scytalidium lignicola agente causal da podridão negra do caule e da raiz de mandioca no estado do Pará. Fitopatologia Brasileira, Brasília, v.22, p. 316, 1997. 